\title{
ASSOCIATION OF CONGENITAL HEART DISEASE, BLEPHAROPTOSIS, AND SHORT STATURE
}

\author{
Tohru Sonoda, Shozo OHdo, Ken-ichi OHBA, \\ Takahiro OKISHIMA, and Kunio HaYaKawA \\ Department of Pediatrics, Miyazaki Medical College, \\ Kiyotake-cho, Miyazaki 889-16, Japan
}

\begin{abstract}
Summary We found 12 patients with congenital heart disease of unknown etiology complicated with blepharoptosis during a period from Sept. 1, 1981 to April 30, 1989. All the patients with congenital heart disease were acyanotic, including 10 with short stature. Among these 10, abnormalities of high frequency were intrauterine growth retardation (5 cases), mental retardation (5), microcephaly (3), epicanthus (4), high arched palate (4), sacral dimple (4), and distal axial triradius (3). It is postulated that the association of congenital heart disease, blepharoptosis and short stature might indicate pathogenetic relationships.
\end{abstract}

Key Words association, congenital heart disease, blepharoptosis, short stature

\section{INTRODUCTION}

Although the combined occurrence of congenital heart disease (CHD), blepharoptosis and short stature has been observed in several recognizable chromosomal syndromes (Jones, 1988), the combination of abnormalities noted in our cases was clearly different from that of heretofore recognized syndromes.

\section{MATERIALS AND METHODS}

Among patients with CHD who visited our outpatient clinic during the period from Sept. 1, 1981 to April 30, 1989, those who were complicated with blepharoptosis were reviewed. We excluded patients with chromosomal aberration or recognizable malformation syndromes.

Received August 4, 1989; revised version received September 28, 1989; Accepted November 21, 1989. 


\section{RESULTS}

Twelve patients had both CHD and congenital blepharoptosis (5 male, 7 female) (Table 1) with 4 left, 1 right, and 7 bilateral. CHD of all patients was acyanotic, including 4 perimembranous ventricular septal defect (VSD), 2 secundum atrial septal defect (ASD), 1 patent ducts arteriosus (PDA), 2 pulmonary stenosis valvular (PSV), 1 aortic stenosis valvular (ASV), and 2 secundum ASD with PSV. Out of these 12 patients, 10 were of short stature. In these 10 , abnormalities other than CHD and blepharoptosis which were of high frequency were 5 intrauterine growth retardation, 5 mental retardation, 3 microcephaly, 4 epicanthus, 4 high arched palate, 4 sacral dimple and 3 distal axial triradius.

Excluding amblyopia found in Cases 9, 10 and 12, patients had no ocular abnormalities other than blepharoptosis. The parents of each patient were unrelated and healthy. The mothers had no histories of spontaneous abortions before the patients were born, except for Cases 2 (once), 7 (once) and 12. (twice). Excluding Cases 9 and 10 who were sisters, there were no family members who showed similar abnormalities. The mothers of patients, except for Cases 6 and 11, whose mother smoked 20 and 5 cigarettes daily respectively during pregnancy, had no prenatal history of exposure to alcohol, smoking, drugs or other teratogens. Five patients out of 12 were born during the months of April and May.

Abnormalities observed in each Case other than listed in Table 1 were following:

Table 1. Patients'

\begin{tabular}{lllll}
\hline Case No. & 1 & 2 & 3 & 4 \\
\hline Day at birth & July 1, 87 & May 17, 80 & Jan 28, 88 & Jan 3, 79 \\
Sex & M & M & M & M \\
Pregnant term & 40 W0D & 41 W3D & 40 W2 & 42 W6D \\
Birth weight (g) & 2,585 & 2,280 & 3,825 & 3,250 \\
Type of CHD & VSD & PDA & PSV & ASV \\
Side of blepharoptosis & L & L & L & B \\
Height (SD) & -2.0 & -1.6 & -1.5 & -1.5 \\
$\quad$ Age) & 1 yr 8 mo & 2 yr 0 mo & 0 yr 11 mo & 14 yr 8 mo \\
Mental retardation & - & - & - & + \\
Microcephaly & - & + & - & - \\
Epicanthus & B & - & B & - \\
High-arched palate & + & - & - & + \\
Sacral dimple & - & - & + & - \\
Distal axial triradius & - & B & - & - \\
Operation for CHD & + & + & - & - \\
\hline
\end{tabular}

M, male; F, female; CHD, congenital heart disease; VSD, perimembranous ventricular septal valvular; ASD, secundum atrial septal defect; $L$, left side; $R$, right side; $B$, bilateral; + , present; 
flat occiput, asymmetric head, hydrocele right testis and proximal implantation of 3rd toes in Case 1; flat occiput, bifid uvula and accesory left nipple in Case 2; left preaxial polydactyly in Case 3 ; prominent forehead, malformed left auricle, scoliosis and bilateral inguinal hernia in Case 4; flat occiput, asymmetric head, prominent forehead, depressed nasal bridge, low-set ears, fistula of left auricle, micropenis, bilateral cryptorchidism, hypospadias, bifid scrotum, short 5th fingers and cerebral cortical atrophy in Case 5; short 5th fingers, and partial syndactyly of 2nd and 3rd toes in Case 6; micrognathia, laterally downward slanting palpebral fissures, bilateral blepharophimosis, wide flat nasal bridge, narrow palate, low-set ears, redundant skin at neck, umbilical hernia, epilepsy, and mild dilatation of the lateral cerebral ventricles in Case 8 ; bilateral blepharophimosis, left preauricular pit, narrow external ear canals, hypoplastic teeth and single right palmar crease in Case 9; bilateral blephrophimosis and hypoplastic teeth in Case 10; left preauricular pit and short 5 th fingers in Case 12. Cases 9 and 10 have been previously reported (Ohdo et al., 1986).

\section{DISCUSSION}

In a large series of patients with CHD, blepharoptosis was reported as 0.96 $\%$, almost 20 times that of the control population (Noonan, 1978). However, there has been only one detailed study of this combination (Larned et al., 1986). This report showed a high incidence of CHD in patients undergoing surgery for

profile.

\begin{tabular}{llllllll}
\hline 5 & 6 & 7 & 8 & 9 & 10 & 11 & 12 \\
\hline Nov 20, 83 & Apr 9, 78 & Oct 9, 84 & May 27, 87 & Feb 24, 70 & Mar 20, 74 Apr 10, 73 & Apr 28, 69 \\
M & F & F & F & F & F & F & F \\
39W2D & 36W5D & 36 W4D & 42 W5D & Full & 40 WD & 42 W0D & 43 W0D \\
1,860 & 2,320 & 2,126 & 2,918 & 3,300 & 2,700 & 2,700 & 3,000 \\
VSD & ASD & VSD & ASD & ASD,PSV & ASD & PSV & ASD,PSV \\
L & B & R & B & B & B & B & B \\
-2.4 & -1.9 & -2.0 & -3.8 & -2.4 & -2.4 & +0.9 & -0.4 \\
2 yr 11 mo & 9 yr 4 mo & 1 yr 5 mo & 1 yr 6 mo & 17 yr 4 mo & 14 yr 5 mo 13 yr 4 mo 8 yr 9 mo \\
+ & - & - & + & + & + & - & + \\
- & + & - & + & - & - & - & - \\
- & B & - & B & - & - & - & B \\
- & - & + & + & - & - & - & - \\
+ & + & - & + & - & - & - & - \\
- & - & - & - & B & B & B & B \\
- & + & - & - & + & - & - & + \\
\hline
\end{tabular}

defect; PDA, patent ductus arteriosus; PSV, pulmonary stenosis valvular; ASV, aortic stenosis - , absent. 
blepharoptosis $(7 / 156=4.4 \%)$. CHD in our cases and in the 7 cases reported by Larned et al. were all acyanotic. The frequency of VSD and ASD in patients with CHD is high, as is that of extracardiac malformation in patients with these lesions (Fyler and Buckley, 1981; Greenwood et al., 1975; Wallgrenet et al., 1978). On the other hand, the frequency of ASV and PSV in patients with CHD and the frequency of extracardiac malformation in such patients is found to be low (Fyler and Buckley, 1981). Consequently, the combination of acyanotic CHD and blepharoptosis might possibly be specific. All CHD observed in our cases belongs to the category of malformations related to altered cardiac hemodynamics, classified as CHD pathogenic mechanisms by Bougman et al. (1987) and Clark (1987). They also suggested a spectrum of CHD associated with decreased right or left heart flow. Secundum ASD and PSV are induced by decreasing right heart flow, whereas ASV is induced as a result of decreasing left heart flow. Although too few cases are present for exact estimate, there seems to be no linkage between the side of blepharoptosis and that of the decreasing heart flow.

On the pathogenesis of a combination of CHD and blepharoptosis, Larned et al. (1986) speculated that an environmental influence acting between the fifth and eighth weeks of gestation might affect the development of muscle fibers both in the heart and in the orbit. Clark (1987) stated that as one of the extracardiac events of the hemodynamic alteration, intrauterine infection in the later stage of

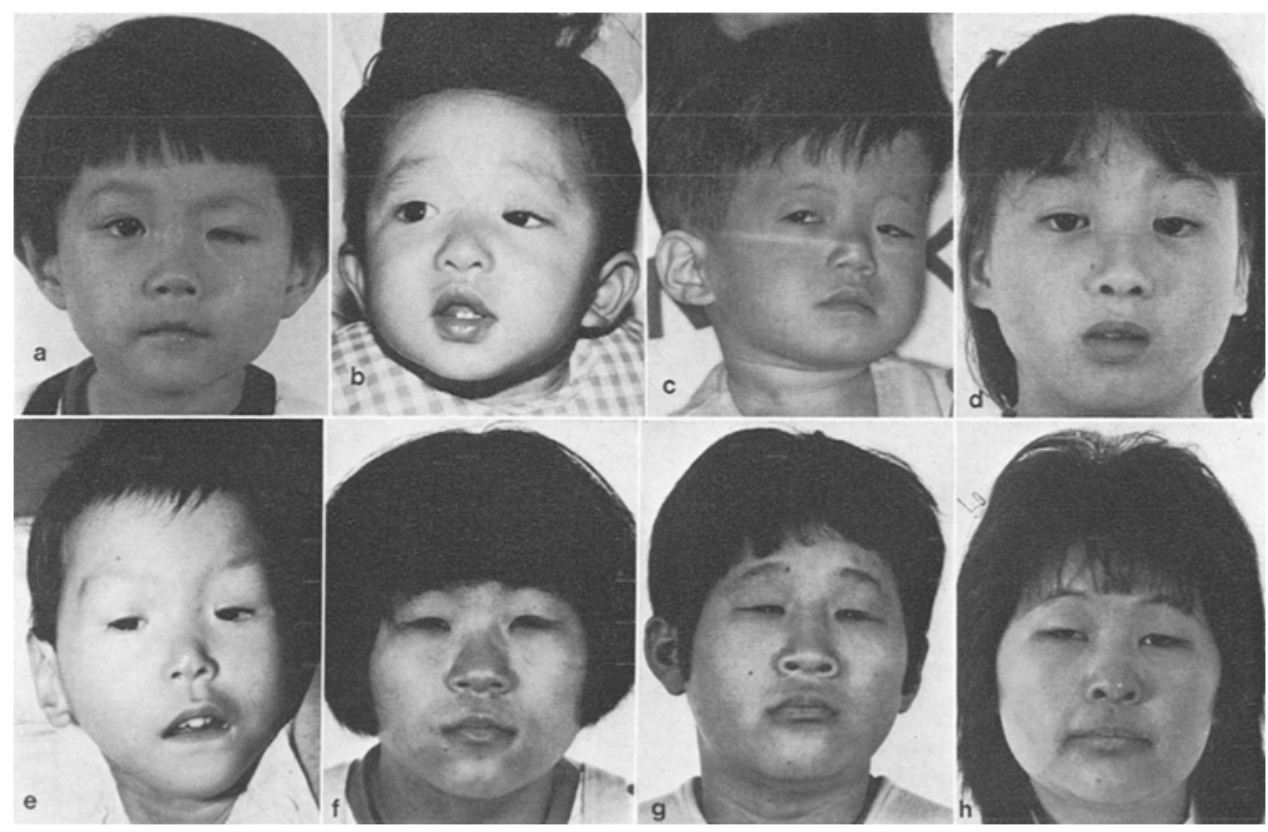

Fig. 1. a: Case 1 at 2 yr; b: Case 3 at 5 mo; c: Case 5 at 2 yr; d: Case 6 at 11 yr; e: Case 8 at $2 \mathrm{yr}$; f: Case 9 at $14 \mathrm{yr}$; : Case 10 at $10 \mathrm{yr}$; h: Case 12 at $17 \mathrm{yr}$. 
development may alter vascular walls, changing the proportion of blood flow. Since no cases have been found with conotruncal cardiac malformations attributable to anomalies of the early embryonic heart, causes might be in the late stage of development. Development of the eyelid starts in the 6th week of gestation, and is completed by the end of the 5th month (Spaeth et al., 1984). On the other hand, blood flowing the embryonic heart probably affects cardiac formation in the late embryonic and fetal stages of development (later than 6 weeks of gestation) (Clark, 1987). Naganuma and Matsuo (1980) suggested that when critical periods of exteracardiac malformation and CHD appear rather widely and randomly distributed throughout gestation, which is the same pattern seen in chromosomal aberration, there is a strong possibility of genetic factors playing an important role, though the possible role of long-term environmental factors, such as environmental pollution can not be ruled out. Cornel et al. (1987) traced coarctation of the aorta and bilateral blepharoptosis in 7 relatives through 4 generations in one family and suggested the possibility of autosomal dominant inheritance.

Among our 12 cases, 10 were complicated with short stature, but it is unlikely that CHD was the direct cause. Of our cases, 4 patients (Cases 1, 2, 6 and 9) underwent heart operations. Except for Case 1, all had mild CHD not involved with heart failure. In Case 1, post-operative catch-up was not observed. It has been conjectured that short stature is not caused by abnormal hemodynamics based on CHD, but is induced by teratogenic agents' action in common with those which induce CHD (Murata and Ikawa, 1982; Shelton, 1980; Yoshitake and Matsuo, 1983). This may be true in our population since 5 cases of 10 with short stature were SFD.

\section{REFERENCES}

Boughman, J.A., Berg, K.A., Astemborski, J.A., Clark, E.B., McCater, R.J., Rubin, J.D. and Ferencz, C. 1987. Familial risks of congenital heart defect assessed in a population-based epidemiologic study. Am. J. Med. Genet. 26: 839-849.

Clark, E.B. 1987. Mechanisms in the pathogenesis of congenital cardiac malformations. In Genetics of Cardiovascular Disease, Pierpont, M.E.A. and Moller, J.H., eds., Martinus Nijhoff Publishing, Boston, pp. 3-11.

Cornel, G., Sharratt, G.P., Virmani, S., Rosales, T. and Lacson, A. 1987. Familial coarctation of the aortic arch with bilateral ptosis: a new syndrome? J. Pediatr. Surg. 22: 724-726.

Fyler, D.C. and Buckley, L.P. 1981. Extracardiac anomalies associated with congenital heart disease. In Associated Congenital Anomalies, El Shafie, M. and Klippel, C.H., eds., The Williams \& Wilkins Co., Baltimore, pp. 125-130.

Greenwood, R.D., Rosenthal, A., Rarisi, L., Fyler, D.C. and Nadas, A.S. 1975. Extracardiac abnormalities in infants with congenital heart disease. Pediatrics 55: 485-492.

Jones, K.L. 1988. Smith's Recognizable Pattern of Human Malformation, 4th Ed., WB Saunders Co., Philadelphia.

Larned, D.C., Flanagan, J.C., Nelson, L.E., Harley, R. and Wilson, T.W. 1986. The association of congenital ptosis and congenital heart disease. Ophthalmology 93: 492-494.

Murata, M. and Ikawa, A. 1982. Nutritional and physical growth problems of patients with con- 
genital heart disease, mainly from a viewpoint of physical growth. Jpn. J. Pediatr. (in Japanese) $35: 2123-2130$.

Nagamuna, M. and Matsuo, N. 1980. Specific associations between congenital heart disease and extracardiac malformations. In Etiology and Morphogenesis of Congenital Heart Disease, Van Praagh, R. and Takao, A., eds., Futura Publishing Co., Mount Kisco, New York, pp. $527-540$.

Noonan, J.A. 1978. Association of congenital heart disease with syndromes or other defects. Pediatr. Clin. N. Am. 25: 797-816.

Ohdo, S., Madokoro, H., Sonoda, T. and Hayakawa, K. 1986. Mental retardation associated with congenital heart disease, blepharophimosis, blepharoptosis, and hypoplastic teeth. $J$. Med. Genet. 23: 242-244.

Shelton, L. 1980. Growth in children with congenital heart disease. In Heart Disease in Infants and Children, Graham, G. and Rossi, E., eds., Edward Arnold, London, pp. 171-177.

Spaeth, G.L., Nelson, L.B. and Beaudoin, A.R. 1984. Ocular teratology. In Biomedical Foundations of Ophthalmology, Vol. 1, Duane, T.D. and Jaeger, E.A., eds., Harper \& Row, Philadelphia, Chap. 40, p. 116.

Wallgren, E.L., Landtman, B. and Rapola, J. 1978. Extracardiac malformations associated with congenital heart disease. Eur. J. Cardiol. 7: 15-24.

Yoshitake, K. and Matsuo, N. 1983. Growth failure and congenital heart disease. J. Pediatr. Practice (in Japanese) 46: 1224-1229. 